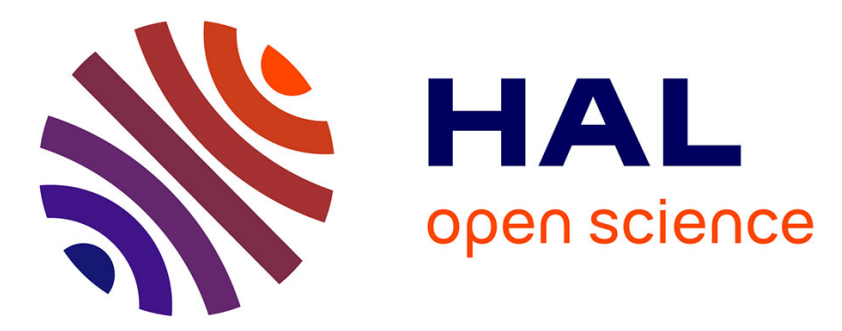

\title{
Autonomous System for UHF RFID Signal Measurement in Industrial Environment
}

Jiri Svub, Pavel Stasa, Filip Benes, Lukas Vojtech, Marek Neruda, Tomas Brozek

\section{- To cite this version:}

Jiri Svub, Pavel Stasa, Filip Benes, Lukas Vojtech, Marek Neruda, et al.. Autonomous System for UHF RFID Signal Measurement in Industrial Environment. 11th IFIP Wireless and Mobile Networking Conference (WMNC 2018), Sep 2018, Prague, Czech Republic. pp.81-86. hal-01995443

\section{HAL Id: hal-01995443 \\ https://hal.inria.fr/hal-01995443}

Submitted on 26 Jan 2019

HAL is a multi-disciplinary open access archive for the deposit and dissemination of scientific research documents, whether they are published or not. The documents may come from teaching and research institutions in France or abroad, or from public or private research centers.
L'archive ouverte pluridisciplinaire HAL, est destinée au dépôt et à la diffusion de documents scientifiques de niveau recherche, publiés ou non, émanant des établissements d'enseignement et de recherche français ou étrangers, des laboratoires publics ou privés.

\section{(c)(1)}

Distributed under a Creative Commons Attribution| 4.0 International License 


\section{Autonomous System for UHF RFID Signal Measurement in Industrial Environment}

\author{
Jiri Svub, Pavel Stasa, Filip Benes \\ Department of Economics and Control Systems \\ VSB - Technical University of Ostrava \\ Ostrava, Czech Republic \\ \{jiri.svub; pavel.stasa; filip.benes\}@vsb.cz
}

\author{
Lukas Vojtech, Marek Neruda, Tomas Brozek \\ Department of Telecommunication Engineering \\ Czech Technical University in Prague \\ Prague, Czech Republic \\ \{vojtecl; nerudmar; brozeto1\}@fel.cvut.cz
}

\begin{abstract}
Deployment of UHF RFID technology in the industrial environment is not easy to perform because of the heterogeneity of the environment, the propagation of the high frequency radio signal, the interference, and the associated timeconsuming implementation. The paper deals with deployment and evaluation of developed autonomous system for measurement of UHF RFID signals in industrial environment. Such a system allows, in defined 3D real-world locations, to obtain autonomously information about the actual Received Signal Strength Indicator of the moving RFID tag (Etalon) that is registered while investigated with each antenna of RFID reader. A corridor was chosen as an experimental area, and Received Signal Strength Indicator was evaluated by both, simulation and measurement methods. The results show a statistically significant relationship between measured and modeled Received Signal Strength Indicator in $\mathrm{dBm}$ at the $99 \%$ confidence level. The presented autonomous system can contribute to a more comprehensive analysis of measuring the electromagnetic field emitted by the UHF RFID antennas in various industrial environments.
\end{abstract}

Keywords-Auto-ID, autonomous system, measuring, radiofrequency signal, RFID technology, visualization

\section{INTRODUCTION}

The UHF (Ultra High Frequency) RFID (Radio Frequency Identification) is a technology that uses electromagnetic fields to automatically identify and track RFID tags attached to the objects. It relies on bi-directional wireless transmission between readers and tags. It is widely used in applications to track the movement of goods in logistics (e.g., in warehouses and shopping areas), to locate objects (property inventory), to leave the perimeter notification (patients in hospitals), etc.

While deploying UHF RFID technology in specific area, it is necessary to consider whether there is any significant risk of interference between UHF RFID means and other technologies in the ISM (Industrial, Scientific and Medical) radio bands, e.g., $868 \mathrm{MHz}$ and $915 \mathrm{MHz}$ for technologies of the Internet of Things (IoT) in Europe and North America/Asia, respectively. Authors in [1] present a review of technologies in the European $868 \mathrm{MHz}$ ISM band and performed interference measurements from $863 \mathrm{MHz}$ to $870 \mathrm{MHz}$ in downtown Aalborg, Denmark. As expected, the UHF RFID technology is fully operational in industrial area and hospital complex for tracking of goods and equipment. The ISM band $865-868 \mathrm{MHz}$ is occupied by strong
RFID reader signals that can prevent the deployment of IoT technologies LoRa and SigFox. The similar review of technologies in the European $868 \mathrm{MHz}$ ISM band is performed in [2]. Authors included not only LoRa and Sigfox but also IoT technology called IQRF. In $868 \mathrm{MHz}$ ISM band, the IQRF operates between $863.15 \mathrm{MHz}$ and $869.85 \mathrm{MHz}$ (central frequencies) with 68 channels and $100 \mathrm{kHz}$ bandwidth [3]. Obligatory operating frequencies for TR-77D transceivers are 867.65 MHz and $869.85 \mathrm{MHz}$, which may be interfered with by UHF RFID technology.

However, interference with other technologies is only a part of the problem of UHF RFID deployment in the area of interest. It is necessary to take into account the surrounding environment, especially the highly conductive surfaces in the vicinity of the tag (metal base, human hand, etc.), high frequency signal reflections, parameters of UHF RFID reader, antenna and tag (transmit power of the reader, tag orientation, antenna polarization, etc.), but also practical implementation (cable lengths, availability of electricity, etc.) [4]. For these reasons, it is therefore extremely important to have information about the reading properties and characteristics of the transmitted signal in location where we intend to implement UHF RFID technology, and also to know the other technologies used in this frequency band in the location.

The easiest way how to measure the electromagnetic field emitted by the UHF RFID antenna is to systematically place the UHF RFID tag on the defined locations and use commercial software such as Impinj Multireader Software [5] to determine the power required to read the RFID tag or register the RSSI (Received Signal Strength Indicator) parameter of the tag response while using a constant power of the UHF RFID reader. This approach requires a lot of manual work, data evaluation, and thus plenty of time, and enables the human error phenomena.

The RFID-equipped mobile robot in a reverse RFID chain concept, i.e., the RFID reader is placed on a mobile device and the tags are placed in fixed positions, is presented in [6]. This concept serves to determine the probable position of the RFID tags. Authors in [7] used set of RFID tags that manually move in the area of interest in order to obtain RFID coverage map. The practical use of the solution represents a considerable manual and time load and cannot be automated. A similarly designed experiment is also a solution for exploring the impact 
of a forklift on an implemented RFID system by both, measurement and simulation methods [8]. Even in this case, the operator is forced to perform the analysis manually, based on his own experience.

Important aspects of UHF RFID signal propagation are presented in [9]. Authors discuss propagation model in free space, propagation model improved on fading and reflections, inter-system and intra-system interference, and 3D view on implementation of UHF RFID technology. The equations for UHF RFID signal propagation is presented in [10]. It takes into account reflections, multipath propagation, tag sensitivity, etc. Simple analysis of the quality of the proposed system by measuring readability is described in [11].

However, position planning for the location of UHF RFID readers in solving of more complex identification or localization problems lies on the level of the experience of system's integrator. In the case of complicated geometries of UHF-equipped RFID technology, it often means to improvise and look for suitable positions and installation of antennas in real-time operation. This increases installation costs, prolongs the installation time, and often reduces the quality of the service being run using UHF RFID technology.

With regard to the above mentioned, one of the goals addressed in this paper is to describe an automated robotic system for measurement of UHF RFID signal in 3D coordinates, especially for industrial applications, which can analyze the spread of the UHF RFID signal before installation work. The simulation of signal propagation is performed in IProp software. Measurement of the RSSI values is performed by automated robotic system in 3D coordinates. Both, measurement and simulation results show statistically significant relationship at the $99 \%$ confidence level.

\section{UHF SIgNAL PROPAGATION}

The standard method for planning signal overage and designing the deployment of high-frequency communication technologies is the use of mathematical models for the propagation of radio-frequency signals. However, these tools are still not used in the area of industrial practice of RFID deployment. The RFID signal propagation analysis and its corresponding readability of the RFID tag at a given distance $r$ from the reader is based on the solution of the standard equation defined in [4]:

$$
r=\left.\frac{\lambda_{0}}{4 \pi} \cdot 4 \sqrt{\frac{k \cdot P_{1} \cdot G_{\mathrm{Reader}}^{2} \cdot G_{\mathrm{T}}^{2}}{P_{3}}}\right|_{k=0 . .4}
$$

The aim is not only to provide enough power to operate the chip inside the RFID tag (using power emitted by the reader $P_{1}$ ) but also to read the RFID tag response (received power $P_{3}$ ) with the level corresponding to the minimum RSSI required on the RFID reader input. If the distribution of attenuation in the given environment is known, the solution of the energy balance of such a data link is a trivial task that can be solved by Friis transmission formula. In practice, sophisticated solutions, which consider multipath propagation and reflections, such as software I-Prop are used [12].

To test the whole system under real conditions, a corridor with a UHF RFID antenna pair was used to realize the position of the persons passing through the corridor (antennas are marked by red and blue points in Fig. 1). Simulation parameters are described in Table II and Table III with respect to mandatory I-Prop setting, and the measurement described below. The signal propagation is simulated with a step $3 \mathrm{~dB}$, which corresponds to the error of the measurement method used in developed UHF RFID system.

The result of the UHF RFID signal propagation for antenna_1 and antenna_2 in the corridor are shown in Fig. 2 and Fig. 3. The color map of the power level distribution corresponds to the scale depicted in Fig. 4. The color spectrum corresponds to the following damping at EIRP (Equivalent Isotropically Radiated Power) $33 \mathrm{dBm}$. When using both antennas in a given corridor, the simulation results show the lowest value above RSSI $-60 \mathrm{dBm}$.

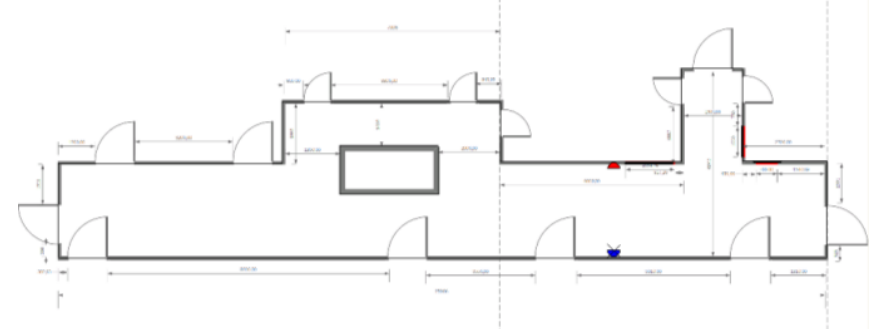

Fig. 1. Scheme of a corridor with marked antenna positions.

TABLE II. MODEL PARAMETERS - LOSS OF WALLS

\begin{tabular}{|c|c|}
\hline Type & Attn. $[\mathbf{d B}]$ \\
\hline Door & 2 \\
\hline Wall (reinforced concrete) & 14 \\
\hline Sheet-metal & 0 \\
\hline
\end{tabular}

TABLE III. MODEL PARAMETERS - GENERAL

\begin{tabular}{|c|c|}
\hline Frequency [MHz] & 868 \\
\hline Power emitted by the reader ANT_1 [dBm] & 33 \\
\hline Power emitted by the reader ANT_2 [dBm] & 33 \\
\hline Height of the antenna above the floor [m] & 1.5 \\
\hline Simulation step of signal propagation [dB] & 3 \\
\hline Loss at 1 m [dB] & 40.7 \\
\hline Propagation index & 2 \\
\hline Offset [dB] & 0 \\
\hline Adjacent floors loss [dB] & 20 \\
\hline Multi-floor parameter 'b' & 0.46 \\
\hline
\end{tabular}

\begin{tabular}{|c|c|c|}
\hline Symbol & Variable & Unit \\
\hline $\boldsymbol{r}$ & distance & $\mathrm{m}$ \\
\hline$\lambda_{\boldsymbol{0}}$ & wavelength & $\mathrm{m}$ \\
\hline $\boldsymbol{k}$ & coupling coefficient & - \\
\hline $\boldsymbol{P}_{\boldsymbol{1}}$ & power emitted by the reader & $\mathrm{W}$ \\
\hline $\boldsymbol{P}_{3}$ & received power & $\mathrm{W}$ \\
\hline $\boldsymbol{G}_{\boldsymbol{R} \text { eader }}$ & gain of the reader`s antenna & $\mathrm{dBi}$ \\
\hline $\boldsymbol{G}_{\boldsymbol{T}}$ & gain of the transponder`s antenna & $\mathrm{dBi}$ \\
\hline
\end{tabular}




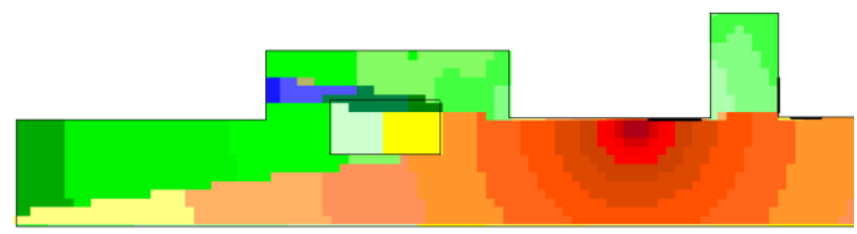

Fig. 2. The result of the UHF RFID signal propagation for antenna_1 in the corridor - relative attenuation of the signal.

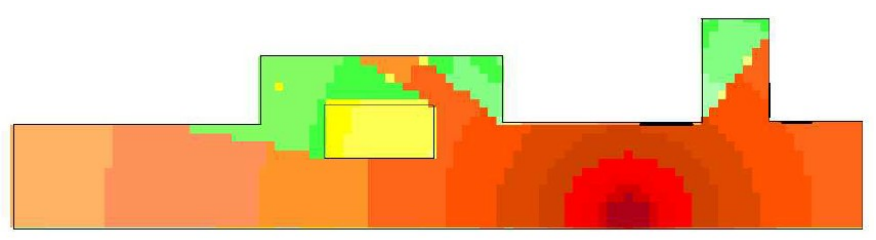

Fig. 3. The result of the UHF RFID signal propagation for antenna 2 in the corridor - relative attenuation of the signal.
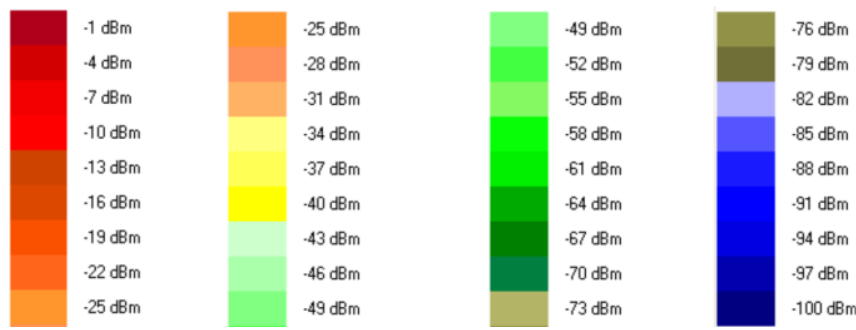

Fig. 4. Color spectrum used in model.

\section{AUTONOMOUS SYSTEM DESCRIPTION}

For measurements in a real environment, it is necessary to implement a system that will not be affected by errors or presence of the operator. At the same time, it is practically necessary for such a system to allow automatic operation and remote monitoring. This allows planning and realization of measurements in various time (e.g., in the coexistence test of different technologies), or at a time when such measurements can be made for technological and operational reasons (night hours, shutdown of off-premises time, etc.). Such a system has been designed and implemented for research and operational needs.

The developed system allows automatic unattended horizontal and vertical measurement of the test area without user presence at the time and place of measurement. The developed autonomous solution is based on a robotic device that allows the UHF RFID tag - Etalon to move on a predetermined route based on black lines placed on the floor and perform a series of measurements at each point on the 3D matrix, Fig. 5. Usage of black lines for route planning offers the most accurate device localization possible for indoor environment.

The mobile module of the measuring system is made up of UHF RFID tag - Etalons, a battery assisted (semi-active) UHF RFID tags, which allow detection of the level of UHF RFID signal even below the threshold of usual passive UHF RFID tag. The great benefit of the proposed solution is fact that UHF
RFID tag - Etalon can move relative to the UHF RFID antennas on a predetermined trajectory both horizontally and vertically using a robotic carriage with a hoist. This solution corresponds to the real application of UHF RFID technology identifying or locating UHF RFID tags. Such a strategy allows a real system testing, including the analysis of extreme operating and boundary conditions (shadowing of tag, inappropriate polarization, impact of obstacles or other coexisting technologies).

The design of each UHF RFID tag - Etalon is based on the use of the EM4325 chip [13] the sensitivity of this Etalon is up to $-38 \mathrm{dBm}$ at the application site and the frequency band 865.6 - 867.6 MHz. This concept is close to a common batteryassisted passive UHF RFID tag. The sensitivity of the chip is up to $-31 \mathrm{dBm}$ (reading range up to $20 \mathrm{~m}$ ), covering the range of UHF RFID Gen2 ETSI frequencies for the EU region: 865.6 - 867.6 MHz (ETSI - European Telecommunications Standards Institute) [14], [15], [16].

The antenna is characterized as a half-wave dipole with dimensions of $150 \times 40 \mathrm{~mm}, 25 \mathrm{~mm}$ above the antenna ground, and the gain of $7.8 \mathrm{dBi}$ while the radiation angle is slightly above 90 degrees, Fig. 6 and Fig. 7.

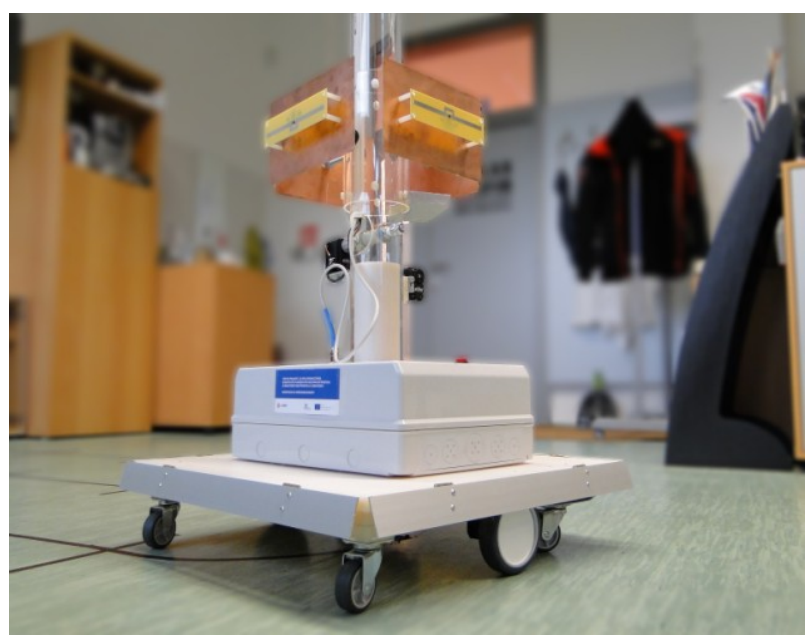

Fig. 5. Autonomous system for measuring of RSSI - UHF RFID tags (Etalons).

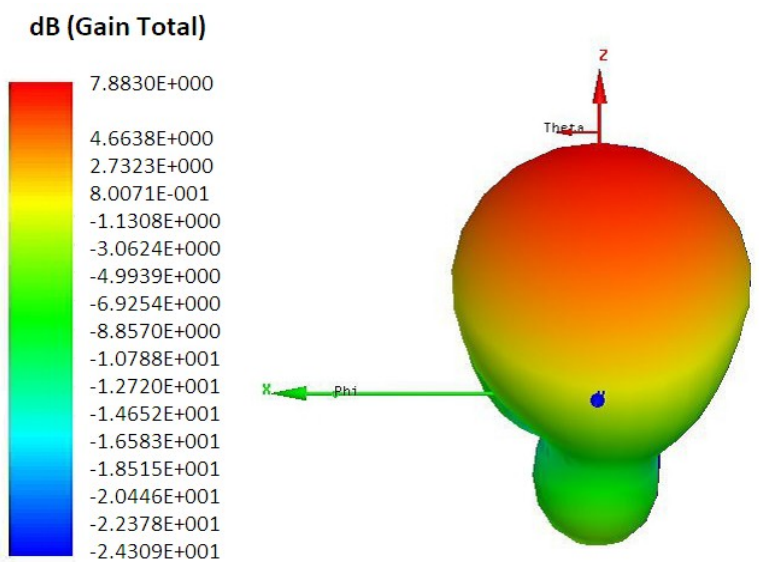

Fig. 6. Radiation pattern; V-plane. 


\section{dB (Gain Total)}
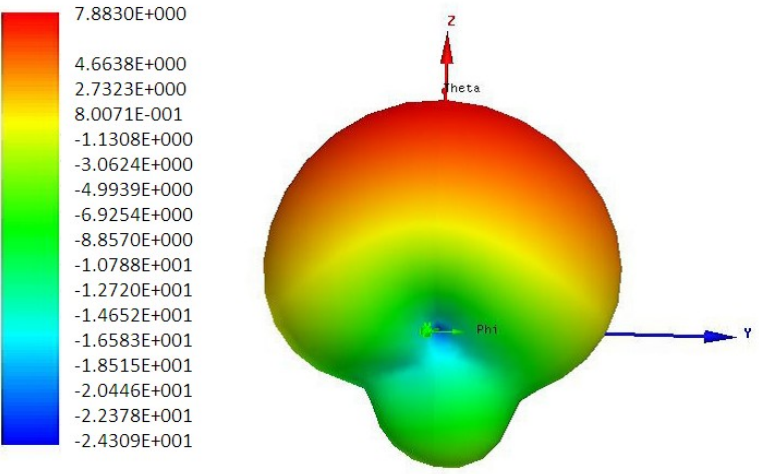

Fig. 7. Radiation pattern; $\mathrm{H}$ - plane.

\section{A. SW Application}

The software application connects the HW measurement system and gives commands to measure at each defined point so that data can be obtained with a $3 \mathrm{D}$ resolution of $\min .50 \mathrm{x}$ $50 \times 50 \mathrm{~cm}$. This step is also chosen in tested situation. The proposed system allows us to get information on the actual UHF RFID reader performance from each antenna that is used to communicate with the UHF RFID tag - Etalon in the given location. Values are then preprocessed and stored in the database where are ready for post-processing. The software in the evaluation process works with data files obtained from 2D and 3D measurements. The output from the measuring software is in the form of many data sets representing the lowest reader power required to retrieve the Etalon at specific coordinates. Visualization provides the user with a clear view of the signal quality at each location of the measured area. The preview of the user interface is shown in Fig. 8.

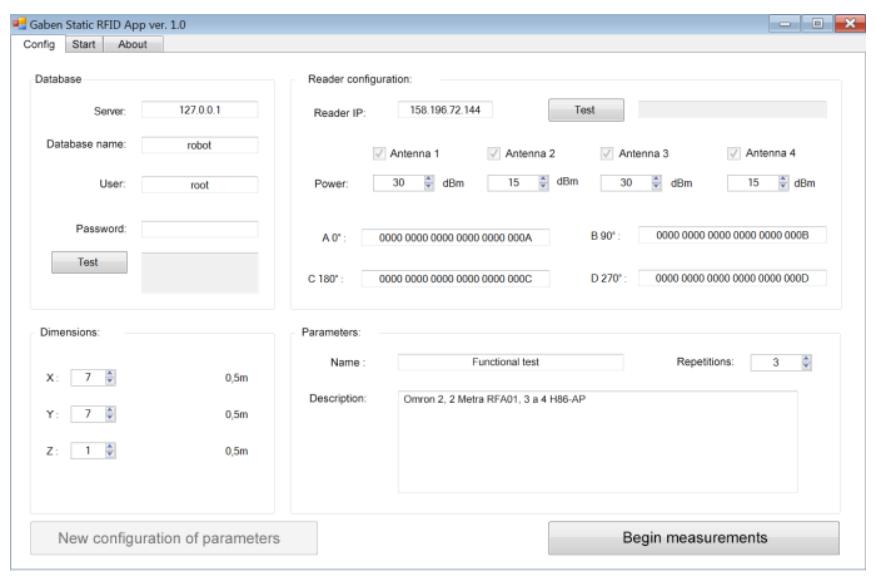

Fig. 8. Application for the RSSI measurement; setting window.

\section{B. Communication technology}

Communication between the SW application and the signal measurement device is based on Bluetooth technology, Fig. 9. The application sends signals to the autonomous system to start the measurement. When the right location is reached, measurement starts. The system saves the value of RSSI after measuring all planned iterations on all planned heights levels at one location. Then the application sends data to the database. Communication between the application and the database is based on Wi-Fi technology.

The system is also able to send notifications to the user by SMS messages, specifically that the measurements have been successfully terminated, that the battery has a low capacity or that a measurement error has occurred, e.g., there was a collision with surroundings.

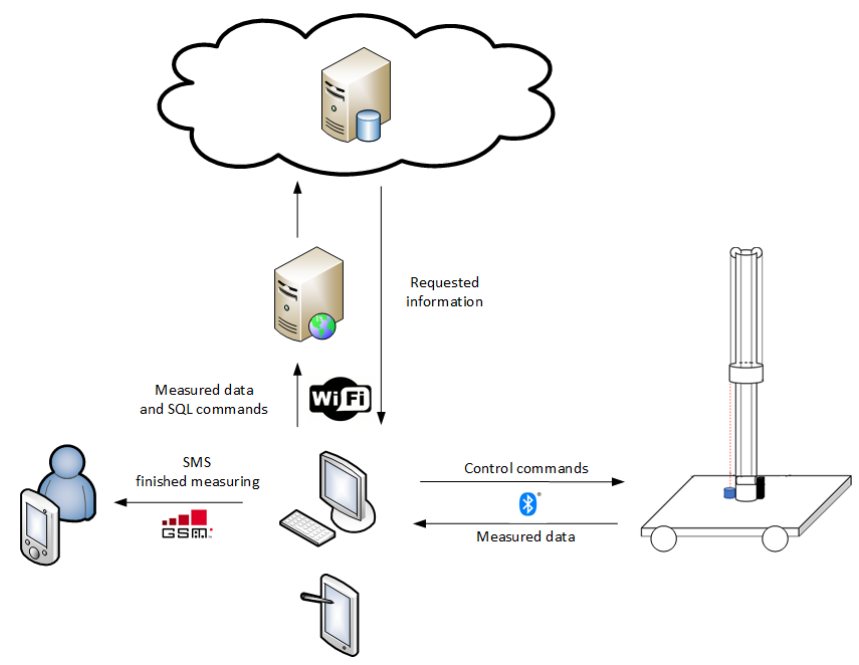

Fig. 9. Communication scheme.

\section{TEST PERFORMED - ANALYSIS AND VISUALIZATION OF MEASURED VALUES}

The whole situation of testing in real environment can be seen in Fig. 10. From practical and industrial reasons (i.e. reading distances are quite enough for industrial applications) it was decided, the maximum size of the measured area in which the proposed 3D measuring system works is $10 \times 10 \mathrm{~m}$ with a height limit of $2 \mathrm{~m}$ divided into 4 levels. The measured area is the part of the corridor shown in the simulation, and the height is chosen with respect to the comparison possibility with the simulation, i.e., $1.5 \mathrm{~m}$.

The data analysis and visualization process can be initiated by a web browser on any device in the WLAN (Wireless Local Area Network). The correct operation of the database is demonstrated by reading all saved measurements. The map of the floor plan can be imported and displayed at the same time as the data, or hidden to focus only on the measured data.

The procedure for selecting individual parameters, including the warning message, is the same as for the module for the analysis of the measured values. The difference here is that the user can select multiple visualization antennas where values in individual cells are rendered based on maximizing the RSSI values. And then there is the option to set the lower and upper limit of the visualized RSSI values.

Visualization of measured RSSI values for each antenna separately can be seen in Fig. 11 and Fig. 12. Antennas are depicted as red and blue rectangle in the $6^{\text {th }}$ column $\left(1^{\text {st }}\right.$ and $5^{\text {th }}$ row). The rows and columns correspond to chosen resolution $50 \times 50 \mathrm{~cm}$. 


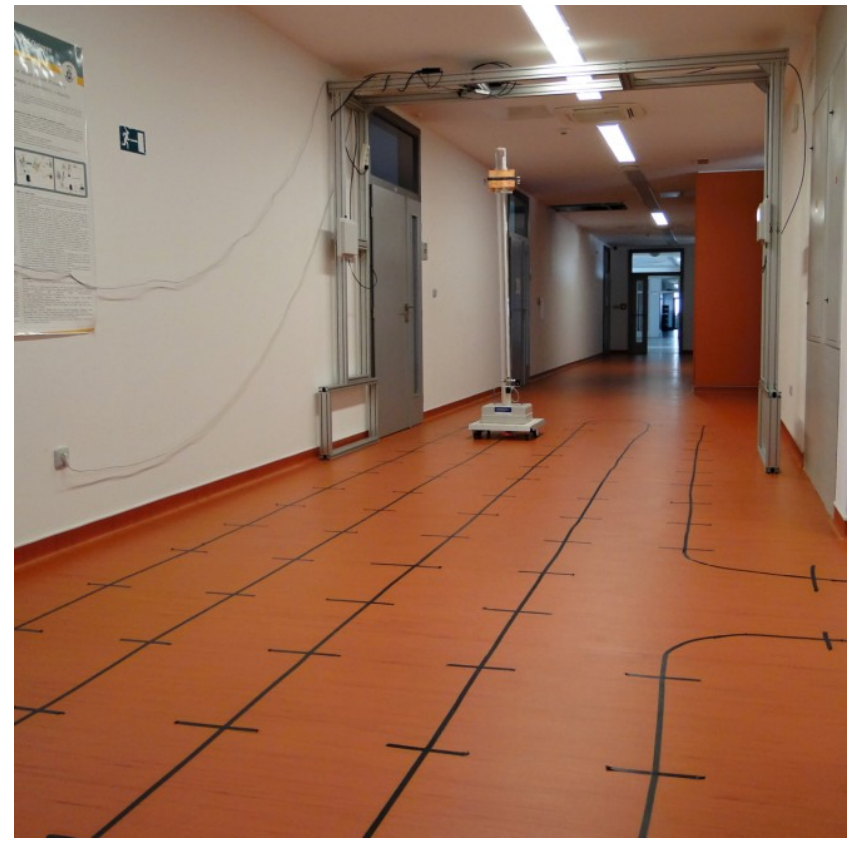

Fig. 10. Autonomous system for measuring of RSSI during the test.

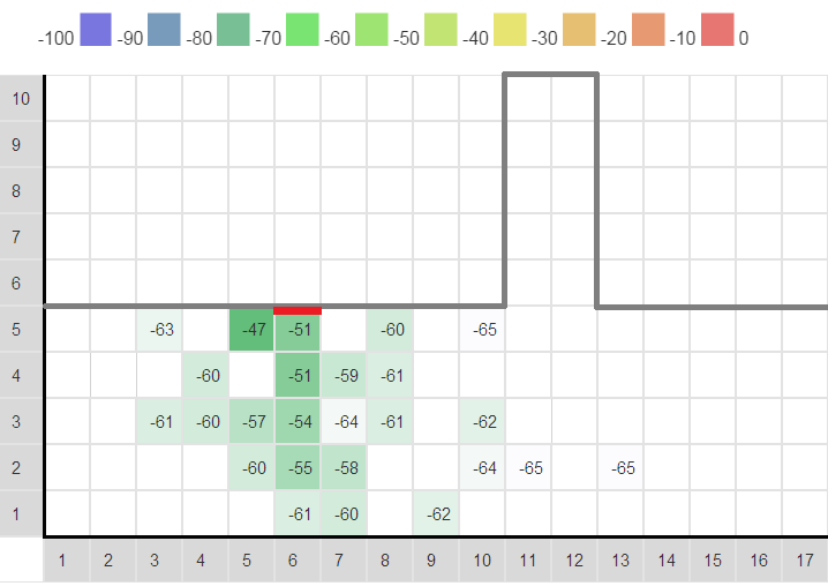

Fig. 11. Visualization of measured data for antenna_1.
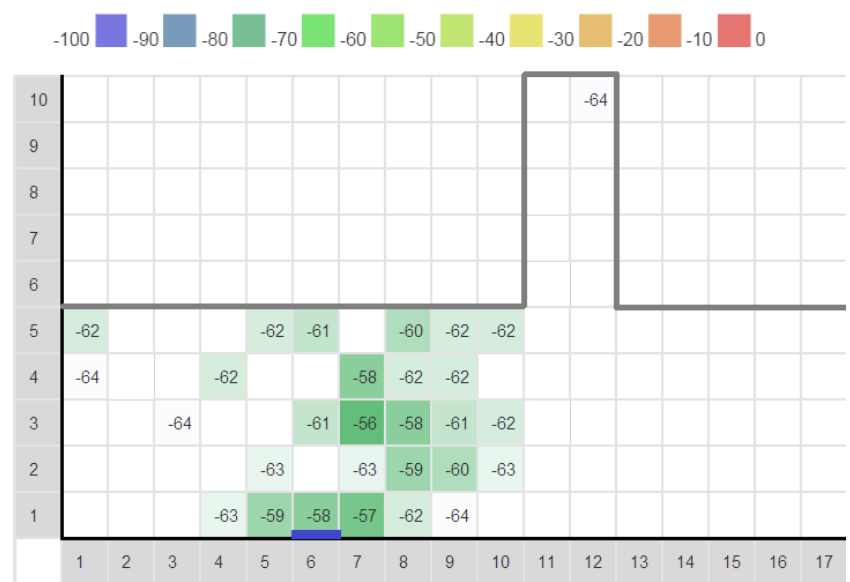

Fig. 12. Visualization of measured data for antenna_2.

\section{EXPERIMENTAL EVALUATION}

In the statistical evaluation of the last experiment we compared measured (RSSI from etalons) and modelled data (RFID reader signal strength). For this purpose we used both data sets (modeled and measured values for reader antenna_1 and antenna_2). Measured RSSI was assumed as the dependent variable and modeled signal strength as independent variable. Based on common second order polynomial regression analysis we used a following relation:

$$
R S S I_{\text {meas }}=53.84+0.91 \cdot d B m_{\text {model }}+0.02 \cdot\left(\mathrm{dBm}_{\text {model }}\right)^{2}
$$

Since the P-value in the ANOVA table is less than 0.01, there is a statistically significant relationship between measured RSSI and modeled $\mathrm{dBm}$ at the $99 \%$ confidence level. The RSquared statistic indicates that the model as fitted explains $42.5 \%$ of the variability in measured RSSI, Fig. 13.

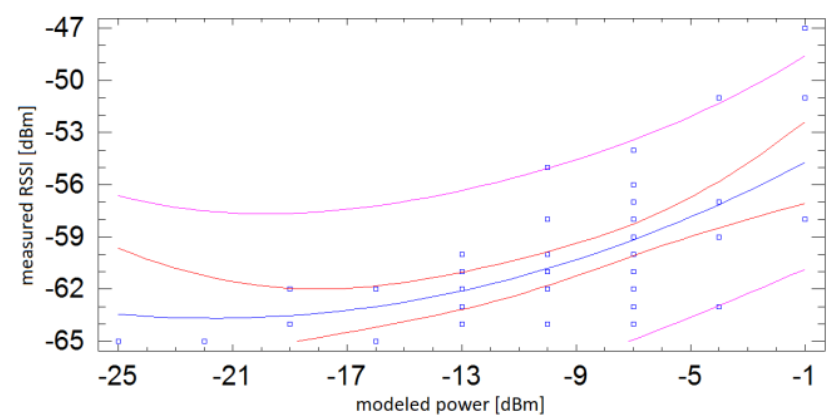

Fig. 13. Plot of second order polynomial regression model.

\section{CONCLUSION}

A system which enables an autonomous UHF RFID signal measurement for various industrial applications was presented in this paper. A series of experiments was performed to demonstrate a new approach how to improve measurements procedures that are required before successful RFID system deployment in real industrial environment. The automated measuring system consisting of a robotic platform is able to move through predetermined trajectory and allows automatically gather actual Received Signal Strength Indicator of the moving RFID tag (Etalon) that is registered while investigated with each antenna of RFID reader. One of the benefits of the proposed solution is fact that RFID tag - Etalon can move relative to the RFID antennas, i.e., correct orientation of tag towards antenna.

Based on performed experimental evaluations, obtained results shows reliable agreement with simulation results while the P-value in the ANOVA table is less than 0.01, what indicates statistically significant relationship.

The models and results shown in this paper could contribute to a more comprehensive analysis of measuring the electromagnetic field emitted by the UHF RFID antenna in 
various industrial environments. No significant differences were found based on the statistical analyses.

For the future improvement of the described system higher sensitivity Etalons should be developed and other progressive ways of data visualization should be tried out including the virtual or augmented reality.

\section{ACKNOWLEDGMENT}

This contribution was supported by the Ministry of Education, Youth and Sport as a part of an Inter-Eureka international project titled "Auto-ID technology and the Internet of Things to enhance the quality of health services" identification number LTE117005, international project code: E! $11158 \mathrm{U}$ Health and by the Technology Agency of Czech Republic as a part of an Delta project titled "IoT Based Intelligent Store" - identification number TF03000053.

\section{REFERENCES}

[1] M. Lauridsen, B. Vejlgaard1, I. Z. Kovacs, H. Nguyen and P. Mogensen, "Interference measurements in the European $868 \mathrm{MHz}$ ISM band with focus on LoRa and SigFox," in: Wireless Communications and Networking Conference (WCNC), 2017 IEEE, 2017. pp. 1-6.

[2] L. Krupka, L. Vojtech and M. Neruda, "The issue of LPWAN technology coexistence in IoT environment," in: MechatronicsMechatronika (ME), 2016 17th International Conference on IEEE, 2016. pp. 1-8.

[3] MICRORISC s.r.o., "IQRF OS, Operating System, Version 4.02D for (DC)TR-7xD, User`s Guide, “IQRF, Jicin, Czech Republic, 2018

[4] K. Finkenzeller, RFID Handbook: Fundamentals and Applications in Contactless Smart Cards, Radio Frequency Identification and Near-Field Communication. West Sussex, UK: John Wiley \& Sons, Ltd., 2010.

[5] Impinj, "Impinj MultiReader Software", Internet: https://support.impinj.com/hc/en-us/articles/202755258-ImpinjMultiReader-Software, 2012-2017 [Apr. 19, 2018].
[6] T. Deyle, Ch. C. Kemp and M. S. Reynolds, "Probabilistic UHF RFID tag pose estimation with multiple antennas and a multipath RF propagation," in: International Conference on Intelligent Robots and Systems, IROS; Nice, France 2008. pp. 1379-1384.

[7] A. A. Goes, P. Cardieri and M. D. Yacoub, "Characterization of the RFID deterministic path loss in manufacturing environments," in: Personal Indoor and Mobile Radio Communications (PIMRC), 2012 IEEE 23rd International Symposium on IEEE, 2012. pp. 647-652.

[8] J. F. Hoefinghoff, A. Jungk, W. Knop and L. Overmeyer, "Using 3D field simulation for evaluating UHF RFID systems on forklift trucks," IEEE Transactions on Antennas and Propagation, 2011, vol. 59 no.2, pp. 689-691.

[9] R. Kueng, "UHF GEN2 RFID Propagation View," Elektrobit Corporation, Amsterdam RFID LIVE Conference 2007, Internet: https://home.zhaw.ch/kunr/NTM1/folien/rfid_propag.pdf, 2007 [Apr. 19, 2018].

[10] P. V. Nikitin and K. V. S. Rao, "Antennas and Propagation in UHF RFID Systems," 2008 IEEE International Conference on RFID, Las Vegas, NV, 2008, pp. 277-288.

[11] J. Mitsugi, "UHF Band RFID Readability and Fading Measurements in Practical Propagation Environment", Auto-ID Lab Japan, Internet: http://cocoa.ethz.ch/downloads/2014/06/None AUTOIDLABS-WPHARDWARE-015.pdf, Sep. 2005 [Apr. 19, 2018].

[12] J. Latal, A. Vanderka, M. Dvorsky and P. Jenicek, "Simulace a plánování vnitřního pokrytí budov dle standardu IEEE $802.11 \mathrm{v}$ prostředí softwarové aplikace I-Prop - 1 část," in: Elektrorevue, 2011, vol. 13 , no. 4 , pp. 1-13.

[13] EM Microelectronic-Marin SA, "EM4325; 18000-63 Type C (Gen2) and 18000-63 Type C / 18000-64 Type D (Gen2/TOTAL) RFID IC", Internet:

http://www.emmicroelectronic.com/sites/default/files/public/products/da tasheets/4325-ds_0.pdf, Sep. 5, 2017 [Apr. 19, 2018].

[14] D.M. Dobkin, The RF in RFID: passive UHF RFID in practise. Burlington: Newnes, 2008.

[15] D. Hunt, A. Puglia, and M. Puglia, RFID: A Guide to Radio Frequency Identification. Hoboken, NJ: John Wiley \& Sons, Inc., 2007.

[16] H. Lehpamer, RFID design principles. Boston: Artech House, 2008. 